\title{
STYLISTIC APPROACH TO TEACHING POETRY IN ESL CLASSROOMS
}

\author{
Leila Tahmasebi \\ Lebanese French University, Iraq \\ leila.tahmasebi72@gmail.com
}

\section{Original Scientific Paper doi:10.5937/jouproman7-22087}

\begin{abstract}
In this study we tried to illustrate the importance of stylistic approach in teaching literature in general and poetry in particular. The context of the study is classrooms of universities featuring ESL classes. The objective is inducing critical thinking and purposeful essay writing based on linguistic features of texts. Initially, we try to have an overall understanding of stylistics by having a glimpse at the concepts of style and stylistics. Deviation and foregrounding the important elements of stylistics are discussed next. Following the introductory section, the main question and the thesis of the paper, the importance of application of stylistics approach in teaching literature in ESL classes, is discussed. The paper is aimed towards a practical exploration of the topic, hence, ESL classroom analysis procedure and levels of the procedure are depicted. The closing section of the paper is a short analysis of a poem by E. E. Cummings based on stylistic approach and its two basic aspects, deviation and foregrounding. In this section the aim is coming to a comprehensive and practical conclusion regarding stylistic approach in teaching poetry.
\end{abstract}

Keywords: poetical analysis, stylistics, deviation, foregrounding.

\section{Stylistic Approach to Teaching Poetry}

Style is the repetition of a specific selected pattern. This selection can be done consciously or unconsciously. For instance, people have a special style of living or speaking but they are not aware of their style, unless for some reason they become conscious of it and decide to change it. Good health or success is the outcome of current life style and a person's prestige and reputation can be the result of good speaking style and behavior. A correct life style includes the recurrence of good habits like eating healthy, daily workout, regular studying and so on. Speaking style results from the lexical choice and syntactical patterns of speaking. The unconscious life style occurs due to the cultural and social background of an individual's life style. Likewise, one can find style in art and literature.

A short glance at the definition of style points to the presence of style in various genres of art. Style can be defined as the distinctive manner in which a work of art is produced. This distinctive manner is the result of a creator's unique way of treating a subject. For instance in music, style is the characteristic arrangement of rhythm, harmony and melody associated with a particular ethnic culture, type or genre. Painting style is the range of colors or brush techniques and paint application defined by a school of thought or an era. Style in literature is the way an author uses words, sentence structures and literary devices to establish the desired effect to convey what he aims for. Let's sum up our introductory argument regarding style with a literary definition of style by Abrams (1993) who defines style as: 
"...the manner of linguistic expression in prose or verse--- it is how speakers or writers say whatever it is that they say. The style of a particular work or writer has been analyzed in terms of the characteristic modes of its diction, or choice of words: its sentence structure and syntax; the density and types of its figurative language; the pattern of its rhythm, component sounds, and other formal features; and its rhetorical aims and devices.”(p.203)

The above definition of style encompasses style both in prose and verse, but since the focus of this paper is on poetry, we continue the paper by solely considering style in poetry.

\section{Stylistics}

Stylistics or linguistic criticism is the study of linguistic features in works of literature. While linguists consider the study of language objectively, literary scholars study language in a more subjective way. Stylistics bridges the gap between the aforementioned views of the linguists and literary critics by making a relation between language and literature. As Simpson (2004) points out, stylistics "enriches our ways of thinking about language" (p.3), so the one-dimensional linguistic observation of the language is expanded towards the multi-dimensional literary observation of it. Stylistics views language far beyond mere symbols by decoding those symbols to explore different layers of meaning and how that meaning is conveyed in the most effective way. In short, stylistics can be considered as the interpretation of literature via language. This approach is very influential in schools and universities in the western world because it gives rise to critical essays about what a text means and how it affects the reader. What is especially more important for stylisticians is deviation from ordinary language which is called foregrounding.

\section{Foregrounding}

Foregrounding reaches far beyond the textual characteristics to a psychological dimension of reading a text. Foregrounding which has been inaugurated by Russian formalists like I. A. Richards, suggests that some parts of texts have more effect on the readers because they are deviant from ordinary language. This fact that foregrounding theory has started from visual arts by making contrasts between colors to make an object more conspicuous and attention grabbing, makes foregrounding effect more significant. In similar manner, for Russian formalists, literary texts generate a special psychological effect on the readers by defamiliarization, by distancing from conventional linguistic structure. Foregrounding is the key term for stylisticians who consider different dimensions of foregrounding in a text. The mentioned aspects of foregrounding enable us to understand the importance of it as an element of stylistic approach to teaching poetry, so as McIntyre(2003)says: "The memorability of a lecture may be explained in part using linguistic foregrounding theory, arguably the cornerstone of stylistic analyses" (p.3). As foregrounding effect presses a poem into the students' minds it is better to have a closer look at foregrounding. 
There are two main types of foregrounding, parallelism and deviation. Parallelism can be described as unexpected regularity. In other words parallelism is the use of components in a sentence that are grammatically the same; or similar in their construction, sound, meaning, or meter. This method adds balance and rhythm to the sentences, giving ideas a smoother flow and persuasiveness, because of the repetition technique which it utilizes. Deviation can be seen as unexpected irregularity. It is the use of a language different from the conventional and everyday language to make a strong impression on the reader's mind. There are different types of deviation: lexical deviation, like neologism which is the invention of new words, grammatical deviation, like an unusual grammatical structure, phonological deviation, such as special pronunciation for the convenience of rhyming and eventually graphological deviation, the strangeness of pronunciation or systems of spelling. In this study, we try to focus on how stylistic approach to teaching poetry in our ESL classrooms can help us have a systematic and cohesive approach to teaching poetry.

\section{Review of Literature}

There are miscellaneous writings about stylistics in literature. Carter and Simpson (1995) consider the aims and methods of stylistics. They point to the significance of theory and the study of its development because they believe literary theory is a prerequisite for literary analysis. Miall and Kuiken (1994) point out the importance of foregrounding effect and they believe foregrounding through affecting the feelings triggers more reading of the work.
They also discuss the reasons behind this kind of readers' reaction to foregrounding effect. Shen (2008) likewise focuses on the marked foregrounding and backgrounding elements of a literary text and the levels of foregrounding effect.

\section{The Problem}

Teaching English literature in ESL classes needs special considerations. There are two major problems which an English literature instructor deals with. One is that when the students encounter the literature of another nation with a different language, they become perplexed and finally frustration overcomes. The second problem is that, since the instructors are also non-English speakers, they need to reach for a systematic way to prevent the first problem. Facing these two major problems, the instructor has to follow a comprehensive method aiming at preventing frustration on the part of the students. One of the newest and most effective methods to be applied in English literature classes is stylistic method. As far as the focus of this study is on teaching poetry, it is essential to see why stylistic approach is a preferred method to teach poetry.

\section{Why Stylistic Approach Is an Appropriate Approach to Teach Poetry?}

One of the best methods of teaching poetry in a non-English speaking context is stylistics. Firstly, the application of this method leaves enough space for the students to discuss. Secondly, it provides both the instructor and the student with a cohesive and systematic way of literary analysis. 
This method limits teacher talking since the instructor's role is limited to priming the students with enough knowledge about poetry, and then monitoring the application of that knowledge by the students. This is a farewell to the conventional ways of lecturing in which the lecturer is a preacher who does not give opportunity to the students to present their ideas or be creative. In this method, active student involvement in the process of learning assists the students in becoming more competent and more confident to interpret and analyze poems independently. Another advantage of this method according to My Van (2009) is that since stylistics deals with language and form, it can "highlight the aesthetic value of literature" hence "the students appreciate the beauty of literary language" (p. 5). Stylistics is an approach towards appreciation, the appreciation of art, and what a writer wants to convey trough his art.

\section{The thesis}

As an approach to teaching poetry in ESL classrooms, stylistics is very comprehensive and cohesive. It is a way of approaching literature in general and poetry in particular through linguistic elements. The realm of linguistics consists of semantical and syntactical aspects of a text. In analyzing a poem by using stylistic approach, the instructor needs a plan based on semantic and syntactic layers of a poem. By practicing a stylistic approach in teaching poetry on semantic and syntactic levels, ESL students find their ways to an independent appreciation to analyze poems.

\section{Stylistic Approach}

ESL students who start studying literature should be primed in two ways. One is gaining enough knowledge of the four skills of English language. The next is being primed with enough knowledge of English literature. In non-English classrooms where the students have initiated studying English literature, they pass many English learning courses until they are well prepared to study literature. Once the students are competent enough, they are primed with sufficient knowledge of English literature. After passing the introductory stages, the students are ready to appreciate and analyze literature using stylistic approach.

Foregrounding and deviation are two important concepts of stylistic analysis. For any given poem the students are encouraged to have a look for any deviation from standard norms of using language. Close studying of a text to explore deviation, is what makes stylistics the best approach to studying English. An in-depth reading of a poem according to Leech(2008) is "a close examination of the language of the poem which leads to a greater understanding of its meaning and value: I. E. to a greater APPRECIATION of it as a work of art"(p. 41). As the students find out the purpose behind the deviation, the power of foregrounding effect impresses them so that an instinctual sense of appreciation of the beauty of the poem directs them towards an imaginative reading of the poem. According to Leech (2008), "foregrounding invites an act of IMAGINATIVE INTERPRETATION by the reader. When an abnormality comes to our attention, we try to make sense of it" (p. 47). 
Using imagination while reading poetry triggers the creative thinking on the part of the students and this ascertains the significance of employing stylistic method for students who are meant to be imaginative, creative and independent interpreters of poetry. In the following sections we try to plan a systematic stylistic teaching method in a poetry class by focusing on deviation and foregrounding effect at the same time.

Before planning any teaching program for a lecture in poetry based on stylistic approach there is an introductory task which should be performed when students are thought a new poem. Before analyzing any poem the students need to understand the poem fully. According to Leech and Short (2007), "The procedure in each case will be to begin with some general first impression of the passage ..." (p. 82). Thus, before analyzing any poem students are asked to grasp the general meaning of the poem individually or in literary circles. The students are assigned to look up the meaning of the new words and in an introductory session share their impressions of the poem as a class. Once the instructor is sure that all the students have understood the meaning of the poem a systematic stylistic analysis of the poem is aroused.

But the instructor is to be sure that the students are primed with enough knowledge of poetic language and literary devices. To do so an easy initiation is essential in ESL classes. Beginning with an easy poem is an essential factor affecting the selection of the poems. Another important factor in selecting a poem for teaching is dominant figures of speech of the selected poem.
The important figure of speech or figures of speech of the poem under study are taught in advance. For example in most ESL classes teaching poetry starts with a poem like "The Eagle,"by Alfred Lord Tennyson (1851). In this poem the dominant figure of speech in this poem is imagery and the structural deviation is both conspicuous and understandable for the students. Therefore the students can find the vivid examples of imagery and understand the examples of grammatical deviation of this poem. Thereafter they try to relate all these findings to the whole semantic body of the poem. The method of initiation paves the way for the students' poetic analysis in a straightforward way.

The class discussion of a poem is divided into two levels, the semantic level and syntactic level. On the semantic level, meaning based and sound based features of poems are discussed. In the semantic level, by the act of decoding language, we try to come to the desired purpose and meaning of the device and the significance of deviation from standard use of language. In the syntactic level, we examine and discus the structure of the poem along with the connection between the normal or deviated structure and the meaning of the poem as a whole. Finally, so long as any piece of a poem is a living whole body of language, we connect our pieces of the findings to come to a concluding appreciation of the poem as a whole. Considering deviation and foregrounding, we come to the coherence of foregrounding which according to Mukarovsky (1964) is "maximum of foregrounding" of a poem not only in the "foregrounded components" but also "in the consistency and systematic character of foregrounding. 
The consistency manifests itself in the fact that the reshaping of the foregrounded component within a given work occurs in a stable direction ..." (p. 44). In a given poem, all elements, including foregrounding elements, work together as a systematic whole. Concluding interpretation of the poem under study is integrated by connecting and relating all the elements and pieces of meaning to the general meaning, and the effect of the poem as a whole.

Deviation, which is a key term of stylistics, can be found in all poetry. Considering deviation, there is no poem that does not lend to stylistic approach of analysis. Based on the view of Levin (1965), " it can be shown that most, if not indeed all, of poetry's characteristic devices exemplify deviation in one way or another" (p. 225). He hints at examples of poetic devices and the deviation they carry in themselves. Rhyme, rhythm, alliteration, metaphor, symbolism, myth and imagery all are elements of poetry that manifest deviation from the normal use of language. The result is the foregrounding effect which elicits the reader and in our case the learners' interest in reading and enjoying the beauty of poetic language. Levin (1965) goes on saying "It is this characteristic of a deviant expression, that of calling attention to itself as object, which gives it its importance in stylistic analysis" (p. 226). So far, we know that the focus of stylistic approach is mostly on deviation, which results in foregrounding effect. In the next section of this study a poem by E. E. Cummings was selected to be analyzed using the stylistic approach.
The reason for selecting E. E. Cummings' poetry is that he is one of the most innovative poets of his time. $\mathrm{He}$ is famous for using eccentric poetic language to create his own style. As an avant-garde poet, he has invented new words, he has reversed grammar of the sentence, and he has sacrificed punctuation in favor of flexibility of his poetic language. Analyzing "Listen" Mclntyre (2004) elaborates on the deviation of the poem by pointing to "the almost constant use of lower case letters where we would normally expect capitals" (p.7). This kind of initial deviation is called graphological deviation which Mclntyre (2004) elaborates by saying," However, one of the effects of this graphological deviation is to foreground any instances where Cummings does use capitalization" (p.7).This example shows us how a poet utilizes foregrounding effect in order to convey what he wants to convey in the most effective and impressive possible way.

E. E. Cummings is also considered one of the best authors of love poems of all time. "I Carry Your Heart With Me" is his most famous love poem. The poem can be compared with a sonnet due to its similar structure, but Cummings adds modern twists to it. It begins with the speaker describing the universal influence of his love in his life and goes on to touch several themes including oneness and love as the originators of life. Its popularity can be ascertained by the fact that its opening line remains to be often tattooed by people and its lines have been used in several works. Before analyzing the poem we have a glimpse at an ESL poetry class. 


\section{ESL Class Analysis Procedure}

Analysis of a poem in a stylistic based ESL classroom, is a three dimensional process. After a full introductory comprehension of the poem which can be more appealing if it is done in groups, the students start identifying the literary features of the poem. This stage can be called the identification stage. In the second stage, which is the exploring stage, the students are encouraged to explore any deviation they can see in the application of the specific identified feature of the poem. The final stage is the concluding stage. In this phase, the students pinpoint the foregrounding effect behind the deviation. All these activities are performed on both semantic and syntactic levels. Following this procedure is sometimes flexible as long as students undergo analyzing different poems, even conventional ones. But the overall form of the procedure is the same. For example, a poem in which there is few or no deviation for the students to identify may be read in the class. In this case, the students just identify the literary devices and make a connection between the device and the content of the poem. Whether the poem is an experimental poem or a conventional one, following this procedure leads the ESL students through the way of a systematic and purposeful interpretation of any poem in an independent way.

\section{Semantic Level}

On the semantic level, sound based and meaning based devices of "[i carry your heart with me (I carry it in]," by E. E. Cummings (1952) are elaborated. Sound based devices include meter, rhyme, alliteration and other specific figures related to the sound pattern of the poem. Meaning based devices are imagery, simile, metaphor and other devices associated to the meaning of the poem. After reading the poem and understanding the meaning of it, our students who have been primed with enough knowledge of poetic language are asked to identify the elements of the poem. For each element the students are asked to spot any deviation they can find in the poem. Eventually the students experience and enjoy the foregrounding effect of the poem. It is in this stage that the learner's creative part of mind is induced towards an active act of creativity. As Leech (2008) puts out, "In addition to the normal process of interpretation which apply to texts, whether literary or not, foregrounding invites an act of imaginative interpretation by the reader. When an abnormality comes to our attention, we try to make sense of it" (p. 61).This can be considered as the ultimate objective of a poetry class, to encourage and lead the students to meditate, contemplate and create ideas.

\section{Syntactic Level}

Hence, Cumming's poetry is outstanding for the graphological deviation, in the syntactic level we focus on the different graphological deviations of his poem. Graphological deviation is all about the shape of the text, capitalization or decapitalization and punctuation. One of the effects of graphological deviation is to foreground any instances of deviation like a painter playing with his brush to stroke a pallet with astonishing figures. 


\section{The Poet}

Estlin Cummings was one of the most idiosyncratic and notable American poets of the twentieth century. His idiosyncrasy is rooted in his intense interest in poetry. He considered himself as a painter and was one the admirers of Pablo Picasso. His poetry was highly visual and he used typography, to say forming patterns in texts, to play more with the form of poems. He played with the established styles of poetry for the benefit of meaning and aesthetics. Aesthetics of his poetry play a role in the way the message is being delivered. His desire was to make people notice their own lives, to break down from the frenzy of our rushing world and all the rules that hold us in place. He accomplished this by using a few techniques in his poem, such as experimenting with form. $\mathrm{He}$ experimented with poetic form and language to create a distinct and personal style. His poetry is best known for his unorthodox usage of both capitalization and punctuation, in which unexpected and seemingly misplaced punctuation sometimes interrupt sentences and even individual words. In "[i carry your heart with me (i carry it in]" the eccentricity of Cummings' poetry is more conspicuous.

\section{Subject and Form}

Cummings has mingled a
conventional subject with an unconventional form. The poem is a love poem in which the speaker is telling his beloved that wherever he goes, he always carries his lover's heart with him. Unlike the conventional sonnet form of love poems, Cummings' use of free verse with four stanzas of varying lengths makes his poem an unconventional love poem.

\section{Semantic Level}

The poem starts with a beautiful metaphor. The students are encouraged and directed by the instructor to identify the metaphorical expression. People cannot really carry a person's heart. Students then explore the deviated use of expression. The speaker carries his beloved heart to point to his depth of his love for her. In this stage students tell the class the foregrounding effect of the metaphor. They can be asked to write the foregrounding effect as an assignment. The same procedure can take place for another unconventional use of language.

The paradoxical phrases throughout the poem engender a sense of clash in the readers' mind only to show that the power of love is the constant dominant force in the speaker's world. " $i$ fear," "no fate," tells the reader he doesn't fear any fate since his lover is his fate or , "I want," "no world," means he doesn't want anything since his beloved means the whole world to him. In groups, the students identify, explore and analyze the foregrounding effect of the paradoxical expressions with the instructor's supervision.

The second stanza contains beautiful imagery. The speaker tells his lover that whatever the moon is it has always been for her, and the sun's song is sung for her, as well. At the same time, Cummings makes use of personification of the moon and the sun. The speaker empowers two huge natural icons by personifying them to serve his beloved. The effect is the powerful love he feels for his dearest. 


\section{Syntactic Level}

On the syntactic level, we explore the grammatical aspects of the poem considering the grammatical deviation. The deviant use of punctuation, unusual bracketing, usage of lower case letters and disruptive word order are typical of Cummings' poetry. As pointed before, one of the main purposes behind any instance of breaking with the standard rules is to foreground. The special punctuation positions are intended to foreground a special motif, inserting brackets serves to insert and foreground feelings and emotions, the use of lowercase letters where we normally expect capitalization is a way to foreground un-capitalized word and, eventually, Cummings plays with the word order to create a sort of unconventional sentence structure, in an attempt to foreground special words and concepts.

In "i carry your heart with me," phrases are bracketed where there is no grammatical need. Brackets are supposed to add something to the text without interrupting the flow of mind. In this poem there is something more to the use of brackets. For example, in lines two and three brackets function with the same purpose but they have got something more to say. The use of brackets foregrounds the idea that the lovers are always connected since they are often together in the same word combination. On the other hand the reader can see the weird lack of spaces between clauses in line four. This technique is utilized to stress and foreground the idea of unity between the lovers. We can find many cases of unspacing throughout the poem.
Cummings frequently uses the pronoun I and all single letters in lower case in the poem. There are different theories as to why Cummings would not capitalize the pronoun. One reason could be the fact that he wants to be the same level with his beloved.

Another instance of graphological deviation in the poem is the run-on lines or enjambment device. Each line flows into the next without any punctuation. It is a sort of deviation from ordinary sentence writing in which the end of the sentence as the unit of meaning, does not finish with full stop but the first stanza is written as one long run-on sentence. The lines do not end in full stops to point to the speakers' limitless love.

\section{Conclusion}

Stylistic approach is an effective method of teaching literature in ESL classes. In this method, a relation between linguistic features and the purpose of a work of art and in our case a poem is made. The focus of this method is on the style, the typical way in which a poet makes use of semantical and syntactical elements of the work towards the ultimate desired objective. All the specific features of stylistic method enable the instructor to plan a purposeful and meaningful method of teaching to assist and prime the learners to become confident and competent enough to analyze a poem so as to write rich and mature essays about poems independently. Gradually the application of this systematic method is internalized by the learners and they become skillful and confident enough to brainstorm new ideas of their own. 
This is an ideal objective of teaching and training non-English language students of literature, who have never been in touch with English literature. Application of this method is a big step forward in the field of teaching literature before. It must be mentioned that any suggested method of teaching should not be inflexible and rigid. What gives life and soul to any classroom teaching is the teacher's creativity to adjust the style of teaching to the specific characteristic of a class. The application of this method joined with the instructors' own teaching strategy, provides the desired outcome in any English literature classes.

\section{References}

Abrams, M. H. (1993). A Glossary of Literary Terms. The United States of America: Holt, Rinehart and Winston.

Carter, R. \& Simpson, P. (Eds).(1995), Language, Discourse and Literature.London: Routledge.

Leech, G. \& Short, M. (2007).A Linguistic Introduction to English FictionalProse. Harlow: Pearson Longman.
Leech, G. (2008). Language in Literature: Style and Foregrounding. Harlow: Pearson Longman.

Levin, S. R. (1965). Internal and external deviation in poetry.Word, 21(2), 225-237. Retrieved from https://doi.org/10.1080/00437956.1965.1143 5425

ManIntyre, D. (2003).Using foregrounding theory as a teaching methodology in astylistic course.Style.37 (1), 1-13.

Mclntyre, D. (2004). Linguistics and literature: stylistics as a tool for the literary critic. Stylistics Research Centre Working Papers 1. Retrieved fromhttps://pdfs. semanticscholar.org

Miall, D. S. \&Kuiken, D. (1994). Foregrounding, defamiliarization, and affect response to literary stories. Poetics, 22, 389407.

Mukarovsky, J. (1964).Standard language and poetic language.A Prague School Reader on Esthetics, Literary Structure, and Style,pp. 17-30.

My Van, T. T. (2009). The relevance of literary analysis to teaching literature in the EFL classroom.English Teaching Forum,47 (3), 2-9.

Simpson, P. (2004).Stylistics: A Resource Book for Students. London: Routledge. 